\title{
New bio-nanocomposites based on iron oxides and polysaccharides applied to oxidation and alkylation reactions
}

\author{
Daily Rodríguez-Padrón, Alina M. Balu, Antonio A. Romero and Rafael Luque*
}

\author{
Full Research Paper \\ Address: \\ Departamento de Química Orgánica, Grupo FQM-383, Universidad \\ de Cordoba, Campus de Rabanales, Edificio Marie Curie (C-3), Ctra \\ Nnal IV-A, Km 396, E14014, Cordoba, Spain \\ Email: \\ Rafael Luque* - q62alsor@uco.es \\ * Corresponding author \\ Keywords: \\ alkylation; benzyl alcohol; benzyl chloride; iron oxide; \\ mechanochemistry; microwave-assisted oxidation; polysaccharide; \\ toluene
}

\author{
Beilstein J. Org. Chem. 2017, 13, 1982-1993. \\ doi:10.3762/bjoc. 13.194
}

Received: 23 May 2017

Accepted: 30 August 2017

Published: 21 September 2017

This article is part of the Thematic Series "Mechanochemistry".

Guest Editor: J. G. Hernández

(ㄷ) 2017 Rodríguez-Padrón et al.; licensee Beilstein-Institut. License and terms: see end of document.

\begin{abstract}
Polysaccharides from natural sources and iron precursors were applied to develop new bio-nanocomposites by mechanochemical milling processes. The proposed methodology was demonstrated to be advantageous in comparison with other protocols for the synthesis of iron oxide based nanostructures. Additionally, mechanochemistry has enormous potential from an environmental pointof-view since it is able to reduce solvent issues in chemical syntheses. The catalytic activity of the obtained nanocatalysts was investigated in both the oxidation of benzyl alcohol to benzaldehyde and in the alkylation of toluene with benzyl chloride. The microwave-assisted oxidation of benzyl alcohol reached $45 \%$ conversion after $10 \mathrm{~min}$. The conversion of the alkylation of toluene in both microwave-assisted and conventional heating methods was higher than $99 \%$ after 3 min and 30 min, respectively. The transformation of benzyl alcohol and toluene into valuable product in both the oxidation and alkylation reaction reveals a potential method for the valorization of lignocellulosic biomass.
\end{abstract}

\section{Introduction}

Heterogeneous catalysis has played a crucial role in the development of the chemical industry. It has allowed the design of more efficient processes, both in an economical and environmental way, thanks to the higher activity and selectivity of heterogeneous catalysts [1-3]. These systems, in particular, are preferred over the use of catalysts in a homogeneous phase due to the difficulty in separation and recovery of the latter. Heterogeneous catalytic systems, as a priority of research activity in the field of green chemistry, open up new possibilities for further development of environmentally friendly, catalyzed processes [4]. In this sense, metal oxide nanoparticles have been extensively studied in recent decades because of their high ac- 
tivity, specificity of interaction and advantageous properties including a high surface/volume ratio combined with their small size [5-7]. Moreover, metal oxide nanoparticles have the additional advantage of easy recycling and reuse, which is an essential and desired property in many applications such as catalysis, sensors and even medicine $[2,6,8,9]$. Our research group has recently prepared different types of metal and metal oxide nanoparticles which have several applications in heterogeneous catalysis [10-14]. Transition metal and metal oxide nanoparticles have been reported to be highly active and selective in several processes, such as redox [15-17], $\mathrm{C}-\mathrm{C}$ and $\mathrm{C}-$ heteroatom couplings $[18,19]$. In particular, iron oxide nanoparticles have been the object of most research from our group over the past years [10,20-22].

One of the main challenges in the field of catalysis is the preparation of new materials to replace the traditional catalysts quickly, cheaply and efficiently [5]. In this regard, mechanochemical synthesis has become one of the most advantageous and environmentally friendly alternatives compared to the traditional routes $[5,23]$. This novel approach offers the possibility of a solvent-free process, avoiding environmental problems related to toxicity and the use thereof $[24,25]$. Moreover, the mechanochemical protocols have potential applicability due to the extreme simplicity, cleanliness, reproducibility and versatility, haven been already demonstrated to be highly useful for the development of a range of advanced nanomaterials including metal-organic frameworks (MOFs), supported metal and metal oxide nanoparticles and nanocomposites with diverse applications in catalysis, sensing, drug delivery and adsorption [25-28]. In addition, mechanochemical protocols have also been employed to functionalize the surfaces of magnetic nanoparticles (MNPs) with monosaccharides [29] and to obtain bio-nanocomposites based on proteins and dopamine (DA)-coated metal oxide MNPs [30,31].

On the other hand, nature has inspired many scientists to innovate and design new materials. The miniaturization and efficiency achieved by entities in nature for energy production, biometabolite, photo-processing and resource maximization has always been an attractive option to imitate based on a fundamental and rational understanding $[28,32]$. In that sense, polysaccharides extracted from fungal organisms can be used both as nanoparticle carriers and sacrificial templates due to their highly functionalized structure. Although such carbohydrates have been widely reported for the preparation of nanocomposites with a great range of applications, due to their low cytotoxicity and notable biocompatibility and stability [33-37], their catalytic application is still lacking. In addition, these natural products are easily and inexpensively produced by microbes, plants, and animals, and constitute a green alternative to synthe- tic polymers in the preparation of nanomaterials, in order to ameliorate environmental issues [34]. Therefore, one of the objectives of this work was to investigate the catalytic behavior of nanocomposites based on iron oxide and the polysaccharide S4, obtained from Lentinus Tigrinus (PS4).

The most promising feature of such nanoentities based on iron oxide and polysaccharides is the bifunctional, oxidative [20] and acidic nature [21], which in turn can be fine-tuned to design highly active materials for both oxidation and acid catalyzed processes.

Among all the known oxidative transformations, the oxidation of alcohols to ketones and aldehydes have gained a lot of attention for the research community due to its broad range of industrial applications $[38,39]$. Nonetheless, the scale up of the oxidation reactions has been very restricted due to the use of heavy metals, the limited selectivity for highly functionalized compounds, and the thermal hazards posed [40]. Consequently, catalytic reactions should be further investigated in order to find new alternatives to conventional oxidation methods that require stoichiometric amounts of inorganic oxidants, which are highly toxic and polluting. Aiming to minimize chemical waste in these catalytic processes, the scientific community is moving towards the use of clean oxidants ("green oxidants"), such as molecular oxygen or $\mathrm{H}_{2} \mathrm{O}_{2}$ [39]. Thus, the use of clean oxidants with heterogeneous catalysts such as $\mathrm{Fe}_{2} \mathrm{O}_{3}$ nanoparticles, Ag nanoparticles supported on hydrotalcites, Au nanoparticles supported on metal oxides, and Pd nanoparticles supported on SBA-15 has been developed [41-44]. In this regard, both unsupported "free" iron oxide nanoparticles [45] and supported iron oxide based catalytic systems [46] have been extensity reported to be active, stable and selective catalysts for the oxidation of alcohols with hydrogen peroxide. Specifically, the oxidation of benzyl alcohol to benzaldehyde has generated great interest in order to study the oxidation of substituted benzyl alcohols. Although benzyl alcohol is industrially produced by reduction of benzaldehyde, this aldehyde is considered as the second most important flavoring molecule after vanillin, due to its variety of applications in cosmetics, perfumes, food, dyes, agrochemicals and pharmaceuticals [41]. Regarding the acid-catalyzed processes, aromatic alkylation reactions are among the most versatile and widely investigated reactions which can grant access to a wide range of compounds as important intermediates, fragrances, agrochemicals and pharmaceuticals [47-49]. In this sense, the benzylation of benzene or other aromatic substrates is well-known to be an important step in the preparation of relevant building blocks in organic synthesis, such as diphenylmethane and substituted diphenylmethanes [50]. Therefore, many studies have been focus on the preparation of novel Lewis 
acid catalysts, such as mesostructured zeolitic materials. In particular, in this study, our research group has focused attention on the alkylation of toluene with benzyl chloride, since is promoted by the presence of Lewis acids such as iron oxides [49].

These two reactions in particular (oxidation and alkylation of benzyl alcohol and toluene, respectively) could find current application in the valorization of lignocellulosic biomass with heterogeneous catalysis.

However, the use of heterogeneous catalysts in the aforementioned reactions usually requires a filtration or centrifugation step to recover the catalyst. In order to simplify the recovery and reuse of the catalytic system, a magnetically separable nanocomposite could represent a breakthrough in the scientific community [51]. Therefore, our research group has focused on the investigation of the aforementioned oxidation and alkylation reactions, using heterogeneous catalysts with magnetic properties.

\section{Results and Discussion}

In the present study, we prepared and analyzed three different catalysts based on iron oxides and polysaccharides, in particular: iron oxide-polysaccharide 4 magnetic nanoparticles $\left(\mathrm{Fe}_{2} \mathrm{O}_{3}\right.$-PS4-MNP), iron oxide-polysaccharide $4\left(\mathrm{Fe}_{2} \mathrm{O}_{3}-\mathrm{PS} 4\right)$ and titanium oxide-iron oxide-polysaccharide $4\left(\mathrm{TiO}_{2}-\mathrm{Fe}_{2} \mathrm{O}_{3}\right.$ PS4) nanocomposites. The materials were successfully obtained using the proposed solvent-free methodology, which is depicted in Figure 1. The materials were characterized by the techniques presented below. The catalytic activity of these systems has been assessed in the alkylation reaction of toluene with benzyl chloride and the selective oxidation of benzyl alcohol to benzaldehyde.

\section{X-ray diffraction}

The structure and arrangement of the synthesized materials were analyzed by X-ray diffraction. The XRD pattern of the $\mathrm{Fe}_{2} \mathrm{O}_{3}$-PS4 nanomaterial exhibited a series of distinctive diffraction lines that could be correlated to the hematite diffraction pattern. A characteristic broad band in the $20^{\circ}$ to $40^{\circ}$ range, a) $\mathrm{FeCl}_{2} \cdot 4 \mathrm{H}_{2} \mathrm{O}$

b) $\mathrm{Fe}\left(\mathrm{NO}_{3}\right)_{3} \cdot 4 \mathrm{H}_{2} \mathrm{O}$, propionic acid

c) $\mathrm{FeCl}_{2} \cdot 4 \mathrm{H}_{2} \mathrm{O}$, titanium isopropoxide

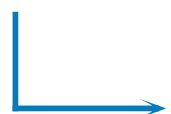

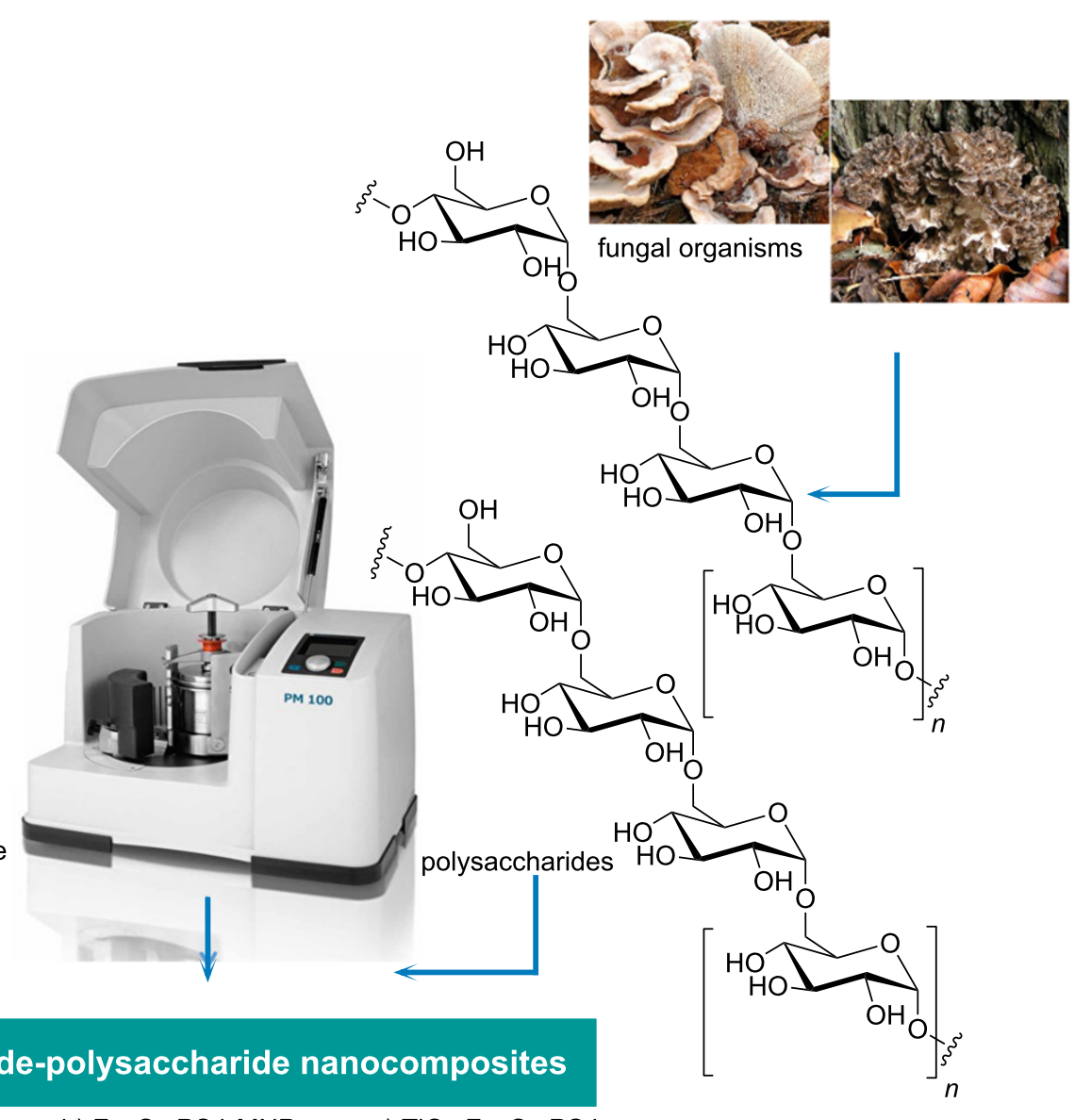

Figure 1: Overview of the preparation of the nanocomposites based on iron oxide and polysaccharide. 
typical of amorphous materials, was observed in the $\mathrm{Fe}_{2} \mathrm{O}_{3}$-PS4 nanomaterial (Supporting Information File 1, Figure S1A). The $\mathrm{X}$-ray diffraction patterns of the magnetic material showed a mixture of maghemite and hematite phases. In this case, a similar XRD pattern could be in principle associated to magnetite $\left(\mathrm{Fe}_{3} \mathrm{O}_{4}\right)$ over the maghemite phase, since these two phases are difficult to clearly distinguish by XRD analysis. However, the absence of $\mathrm{Fe}^{2+}$ species (see the following XPS analysis) and the reddish color are consistent with a maghemite magnetic phase (Supporting Information File 1, Figure S1B) [51,52]. On the other hand, the crystal structure of the material $\mathrm{TiO}_{2}-\mathrm{Fe}_{2} \mathrm{O}_{3}-$ PS4 turned out to be a mixture of ilmenite and pseudobrookite phases (Supporting Information File 1, Figure S1C).

\section{X-ray photoelectron spectroscopy}

X-ray photoelectron spectroscopy (XPS) measurements were consistent with XRD data, where the main peaks were found to correspond to $\mathrm{Fe}_{2} \mathrm{O}_{3}$ species. In the three nanocomposites, the presence of $\mathrm{Fe}^{3+}$ species could be also inferred from the Fe $2 p_{3 / 2}$ and $F e 2 p_{1 / 2}$ peaks around $710 \mathrm{eV}$ and $725 \mathrm{eV}$, respectively (Figure 2). These results are in good agreement with previous studies and did not show the characteristic peak associated with the presence of $\mathrm{Fe}(\mathrm{II})$ or $\mathrm{Fe}(0)$ species in the materials $[51,52]$. Concerning the $\mathrm{TiO}_{2}-\mathrm{Fe}_{2} \mathrm{O}_{3}$-PS4 nanocatalyst, the XPS experiments results revealed a band at $462 \mathrm{eV}\left(\mathrm{Ti} 2 \mathrm{p}_{3 / 2}\right)$, which confirmed the presence of $\mathrm{TiO}_{2}$ on the surface of the nanocomposite (Figure 2C). Additionally, the deconvoluted
C 1s XPS spectra of the obtained materials exhibited two different contributions associated to the presence of $\mathrm{C}-\mathrm{C} / \mathrm{C}=\mathrm{C}$ and $\mathrm{C}-\mathrm{O}$ bonds. Also, the $\mathrm{O} 1 \mathrm{~s}$ XPS spectra for the $\mathrm{Fe}_{2} \mathrm{O}_{3}-\mathrm{PS} 4$ and $\mathrm{Fe}_{2} \mathrm{O}_{3}$-PS4-MNP nanomaterials displayed two different peaks attributed to $\mathrm{O}-\mathrm{C}$ and $\mathrm{O}-\mathrm{Fe}$, while for the $\mathrm{TiO}_{2}-\mathrm{Fe}_{2} \mathrm{O}_{3}-\mathrm{PS} 4$ nanocomposite contained three contributions related to $\mathrm{O}-\mathrm{C}$, $\mathrm{O}-\mathrm{Ti}$ and $\mathrm{O}-\mathrm{Fe}$ (see also Supporting Information File 1, Figures S2-S4 for the XPS spectra).

\section{Nitrogen physisorption}

The textural properties of the materials have been studied with $\mathrm{N}_{2}$ absorption-desorption isotherms analysis. The $\mathrm{TiO}_{2}-\mathrm{Fe}_{2} \mathrm{O}_{3}-$ PS4 nanomaterial presents a mesoporous structure with a pore size of $20 \mathrm{~nm}$ and a surface area of $58 \mathrm{~m}^{2} / \mathrm{g}$. However, in the other two catalysts, a particular macroporosity was found at $p / p_{0}>0.98$ (isotherms of type III), which are clearly dissimilar to those of conventionally ordered mesoporous materials [53] having a sharp increase in $p / p_{0}$ from 0.85 to 0.90 (see Supporting Information File 1, Figure S5 for all adsorption-desorption isotherms). Thus, the $\mathrm{Fe}_{2} \mathrm{O}_{3}$-PS4 and the $\mathrm{Fe}_{2} \mathrm{O}_{3}$-PS4-MNP material are macroporous solids with interparticle pores. The surface area was found to be 33 and $6 \mathrm{~m}^{2} / \mathrm{g}$ for $\mathrm{Fe}_{2} \mathrm{O}_{3}$-PS4-MNP and for $\mathrm{Fe}_{2} \mathrm{O}_{3}$-PS4 nanomaterials, respectively. The pore volumes were found to be in the range of $0.30-0.40 \mathrm{~mL} / \mathrm{g}$ for the three materials (Table 1). The materials exhibited, in general, satisfying surface areas and pore volumes, particularly taking into account their preparation methodology.
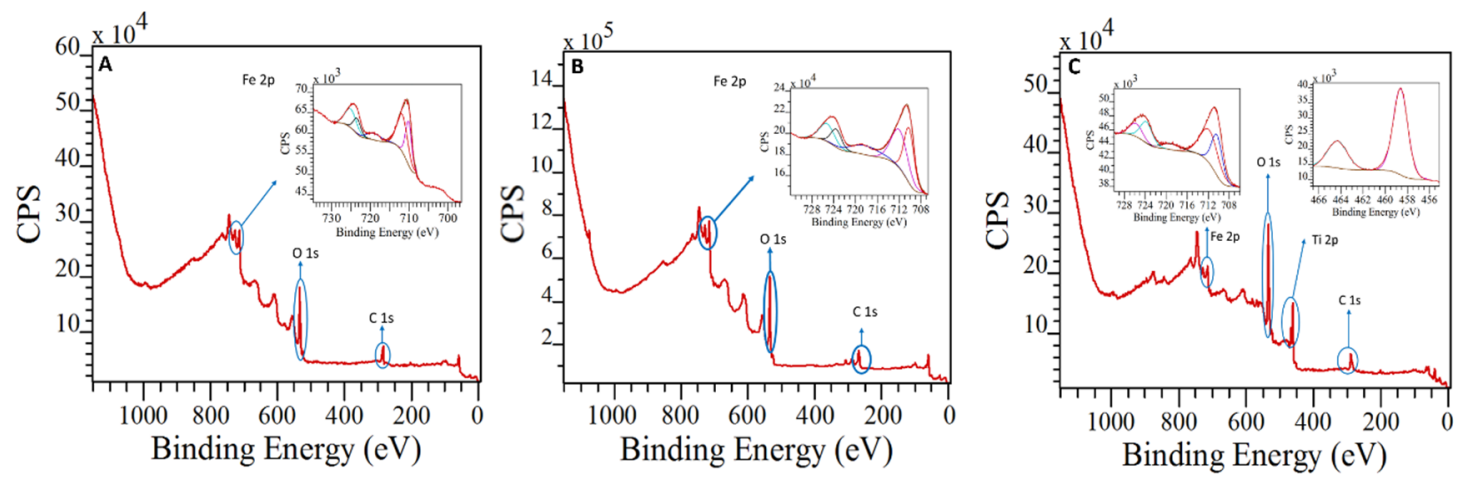

Figure 2: XPS spectra of $\mathrm{A}$ : $\mathrm{Fe}_{2} \mathrm{O}_{3}-\mathrm{PS} 4, \mathrm{~B}: \mathrm{Fe}_{2} \mathrm{O}_{3}-\mathrm{PS} 4-\mathrm{MNP}$ and $\mathrm{C}: \mathrm{TiO}_{2}-\mathrm{Fe}_{2} \mathrm{O}_{3}-\mathrm{PS} 4$ nanohybrids.

Table 1: Textural properties of iron oxide/polysaccharide nanohybrids.

\begin{tabular}{lccc} 
Catalyst & $\mathrm{TiO}_{2}-\mathrm{Fe}_{2} \mathrm{O}_{3}-\mathrm{PS} 4$ & $\mathrm{Fe}_{2} \mathrm{O}_{3}-\mathrm{PS} 4-\mathrm{MNP}$ & $\mathrm{Fe}_{2} \mathrm{O}_{3}-\mathrm{PS}_{4}$ \\
\hline$S_{\text {BET }}\left(\mathrm{m}^{2} / \mathrm{g}\right)$ & 58 & 33 & 6 \\
$D_{\text {BJH }}(\mathrm{nm})$ & 20.9 & 41.2 & 171.2 \\
$V_{\text {BJH }}(\mathrm{mL} / \mathrm{g})$ & 0.32 & 0.36 & 0.40
\end{tabular}




\section{Electron microscopy}

The morphology of the nanomaterials was determined by scanning electron microscopy (SEM) and transmission electron microscopy (TEM). The micrographs show a homogeneous distribution of iron oxide nanoparticles for the three catalysts (Figure 3A,C,E). The analysis of the SEM images reveals the tendency of the constituent particles of the magnetic material to form agglomerates due to their nanometer size (Figure 3E). When these agglomerates are observed at higher magnification, they can be seen as independent particles. The three materials displayed a similar particle-size distribution average of around $9 \mathrm{~nm}, 12 \mathrm{~nm}$ and $10 \mathrm{~nm}$ for the $\mathrm{TiO}_{2}$ -
$\mathrm{Fe}_{2} \mathrm{O}_{3}$-PS4, $\mathrm{Fe}_{2} \mathrm{O}_{3}$-PS4 and $\mathrm{Fe}_{2} \mathrm{O}_{3}$-PS4-MNP, respectively (Figure 3B,D,F).

\section{Diffuse reflectance infrared Fourier transform spectroscopy}

The acidic properties of the $\mathrm{Fe}_{2} \mathrm{O}_{3}-\mathrm{PS} 4-\mathrm{MNP}$ and $\mathrm{TiO}_{2}-\mathrm{Fe}_{2} \mathrm{O}_{3}-$ PS4 materials were studied by diffuse reflectance infrared Fourier transform spectroscopy (DRIFT) experiments. The $\mathrm{TiO}_{2}-\mathrm{Fe}_{2} \mathrm{O}_{3}$-PS4 nanocomposite has well-marked acidic characteristics. This can be deduced from the intense and welldefined bands observed at 1449 and $1600 \mathrm{~cm}^{-1}$, which can be attributed to Lewis acid centers (Figure 4A). Additionally, in
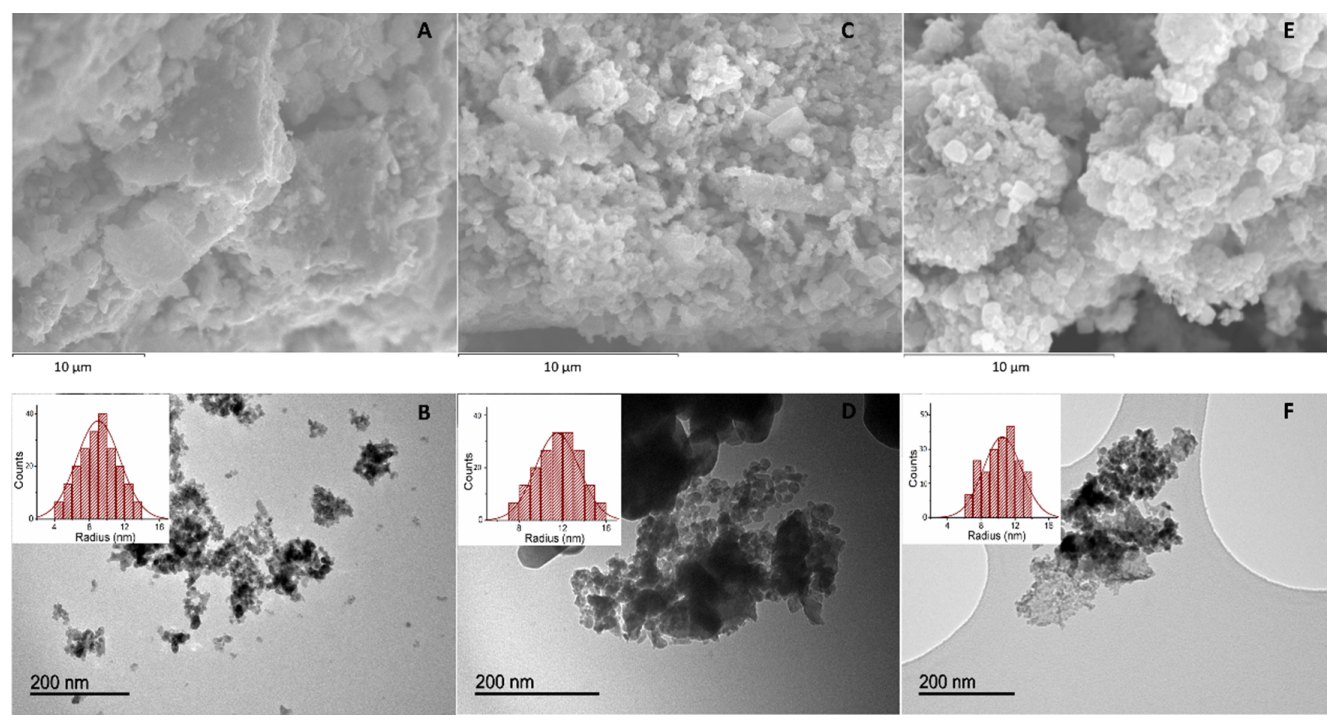

Figure 3: $\mathrm{A}$ and $\mathrm{B}$ : SEM and TEM images of $\mathrm{TiO}_{2}-\mathrm{Fe}_{2} \mathrm{O}_{3}-\mathrm{PS} 4 ; \mathrm{C}$ and D: SEM and TEM images of $\mathrm{Fe}_{2} \mathrm{O}_{3}-\mathrm{PS} 4$. E and F: SEM and TEM images of $\mathrm{Fe}_{2} \mathrm{O}_{3}$-PS4-MNP. Inset: Particle-size distribution of the obtained nanohybrids.
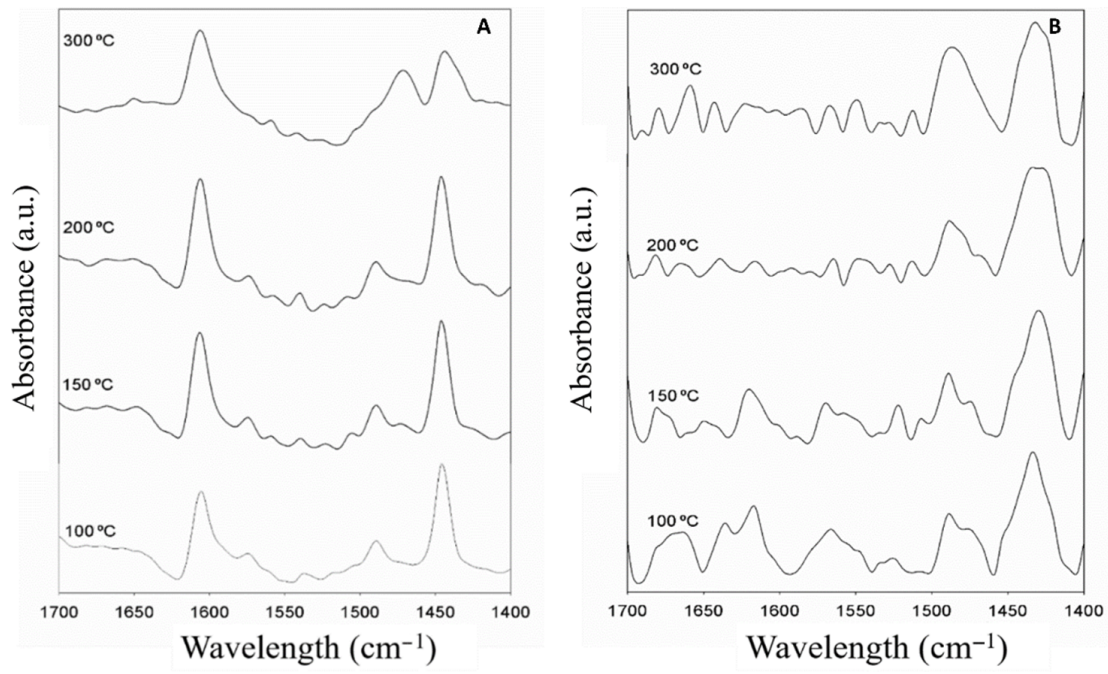

Figure 4: DRIFT spectra of $\mathrm{A}$ : $\mathrm{TiO}_{2}-\mathrm{Fe}_{2} \mathrm{O}_{3}-\mathrm{PS} 4$ and $\mathrm{B}$ : $\mathrm{Fe}_{2} \mathrm{O}_{3}-\mathrm{PS} 4-\mathrm{MNP}$ nanohybrids. 
the spectrum of $\mathrm{Fe}_{2} \mathrm{O}_{3}-\mathrm{PS} 4-\mathrm{MNP}$, having bands at 1440 and $1618 \mathrm{~cm}^{-1}$, indicates the peculiar Lewis acidity of this material (Figure 4B). Furthermore, in both materials, a band of lesser intensity can be seen around $1490 \mathrm{~cm}^{-1}$, which is due to the presence of both Brønsted and Lewis centers.

These materials maintained a remarkable acidity, even at high temperatures $\left(200\right.$ and $300{ }^{\circ} \mathrm{C}$ ) with visible acid centers distinguishable from noise. This behavior has a high value for acidcatalyzed processes such as alkylation. Furthermore, the $\mathrm{Fe}_{2} \mathrm{O}_{3}-$ PS4 sample does not show appreciable acidity [43].

\section{Pyridine (PY) and 2,6-dimethylpyridine (DMPY) titration}

The acidic properties of these materials have also been determined by the chromatographic method of pulses. Pyridine, due to low steric hindrance, adsorbs nonspecifically in both types of centers, while dimethylpyridine adsorbs specifically on Brønsted acid centers, due to the high steric hindrance of the methyl groups [54]. It is noticeable that the $\mathrm{TiO}_{2}-\mathrm{Fe}_{2} \mathrm{O}_{3}-\mathrm{PS} 4$ catalyst possesses both Lewis and Brønsted acid sites with a more marked Lewis acidity. The $\mathrm{Fe}_{2} \mathrm{O}_{3}$-PS4-MNP material presents instead only Lewis acid sites, while the $\mathrm{Fe}_{2} \mathrm{O}_{3}$-PS4 does not show appreciable acidity to be quantized (Table 2).

Acidity measurements from both methodologies (PY DRIFT, PY and DMPY pulse chromatography titration data) were generally in good agreement, supporting the validity of our assumption on DMPY adsorbing selectively on Brønsted acid sites.

\section{Inductively coupled plasma-mass spectrometry (ICP-MS)}

The elemental composition of the $\mathrm{TiO}_{2}-\mathrm{Fe}_{2} \mathrm{O}_{3}$-PS4 material was determined by ICP-MS. The content of iron and titanium was 38 and 12 wt $\%$, respectively (Table 3 ). These values corroborate the incorporation of titanium in the material and confirm the results obtained by XPS.

\section{Magnetic susceptibility}

The magnetic susceptibility of $\mathrm{Fe}_{2} \mathrm{O}_{3}$-PS4-MNP is consistent with the XRD data and confirms the magnetic characteristics of the material. Such values make this a material with attractive feature for magnetic separation (Table 4) [40].
Table 3: Elemental composition of the $\mathrm{TiO}_{2}-\mathrm{Fe}_{2} \mathrm{O}_{3}-\mathrm{PS} 4$ nanohybrid material.

\begin{tabular}{cc} 
Element & ICP-MS (wt \%) \\
\hline $\mathrm{Ti}$ & 12.8 \\
$\mathrm{Fe}$ & 38.3 \\
\hline
\end{tabular}

\begin{tabular}{|c|c|c|}
\hline Catalyst & $\begin{array}{l}\text { Milling time } \\
\qquad(\min )\end{array}$ & $\begin{array}{l}\text { Magnetic susceptibility } \\
\qquad\left(10^{-6} \mathrm{~m}^{3} \mathrm{~kg}^{-1}\right)\end{array}$ \\
\hline \multirow[t]{2}{*}{$\mathrm{Fe}_{2} \mathrm{O}_{3}-\mathrm{PS} 4-\mathrm{MNP}$} & 15 & 420 \\
\hline & 30 & 337 \\
\hline
\end{tabular}

\section{Catalytic activity}

The catalytic activity of these materials has been investigated in two reactions: 1) the oxidation of benzyl alcohol to benzaldehyde and the 2) alkylation of toluene with benzyl chloride.

The oxidation reaction of benzyl alcohol was carried out using the three nanomaterials as heterogeneous catalysts (Scheme 1). The results of conversion and selectivity are reported in Table 5 and Figure 5. After $10 \mathrm{~min}$, the conversions were 32 and $45 \%$ for $\mathrm{TiO}_{2}-\mathrm{Fe}_{2} \mathrm{O}_{3}-\mathrm{PS} 4$ and $\mathrm{Fe}_{2} \mathrm{O}_{3}$-PS4 nanomaterials, respectively, while for the $\mathrm{Fe}_{2} \mathrm{O}_{3}$-PS4-MNP catalyst the conversion reaches just $10 \%$. Remarkably, the selectivity to benzaldehyde, employing $\mathrm{Fe}_{2} \mathrm{O}_{3}$-PS4 nanocatalysts, was higher than $90 \%$ for a reaction time of 5 and $10 \mathrm{~min}$. Since the best results were obtained with the $\mathrm{Fe}_{2} \mathrm{O}_{3}$-PS4 nanocomposite, the latter was employed to carry out the reaction for $30 \mathrm{~min}$ in order to improve the obtained results. However, the conversion increased only to

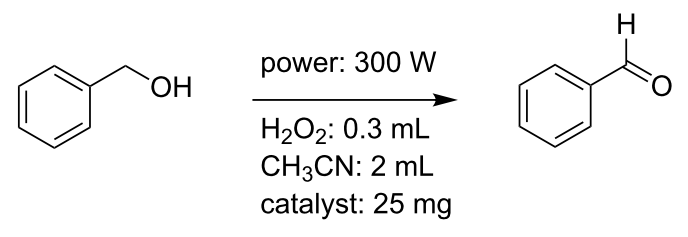

Scheme 1: Oxidation of benzyl alcohol to benzaldehyde.

Table 2: Surface acidity of iron oxide/polysaccharide nanohybrids.

\begin{tabular}{lccc} 
Catalyst & Total acidity PY $(\mu \mathrm{M} / \mathrm{g})$ & Brønsted acidity DMPY $(\mu \mathrm{M} / \mathrm{g})$ & Lewis acidity $(\mu \mathrm{M} / \mathrm{g})$ \\
\hline $\mathrm{TiO}_{2}-\mathrm{Fe}_{2} \mathrm{O}_{3}-\mathrm{PS} 4$ & 81 & 25 & 56 \\
$\mathrm{Fe}_{2} \mathrm{O}_{3}$-PS4-MNP & 14 & - & 14
\end{tabular}




\begin{tabular}{|c|c|c|c|c|c|c|}
\hline \multirow{2}{*}{$\begin{array}{c}\text { Catalyst } \\
\text { Time (min) }\end{array}$} & \multicolumn{2}{|c|}{$\mathrm{TiO}_{2}-\mathrm{Fe}_{2} \mathrm{O}_{3}-\mathrm{PS} 4$} & \multicolumn{2}{|c|}{$\mathrm{Fe}_{2} \mathrm{O}_{3}-\mathrm{PS} 4$} & \multicolumn{2}{|c|}{$\mathrm{Fe}_{2} \mathrm{O}_{3}-\mathrm{PS} 4-\mathrm{MNP}$} \\
\hline & $\mathrm{C}^{\mathrm{a}}(\%)$ & $S^{b}(\%)$ & $\mathrm{C}^{\mathrm{a}}(\%)$ & $\mathrm{S}^{\mathrm{b}}(\%)$ & $\mathrm{C}^{\mathrm{a}}(\%)$ & $S^{b}(\%)$ \\
\hline 5 & 30 & 76.6 & 18 & 94.4 & 10 & 24.4 \\
\hline 10 & 32 & 78.1 & 45 & 97.7 & 10 & 24.7 \\
\hline
\end{tabular}

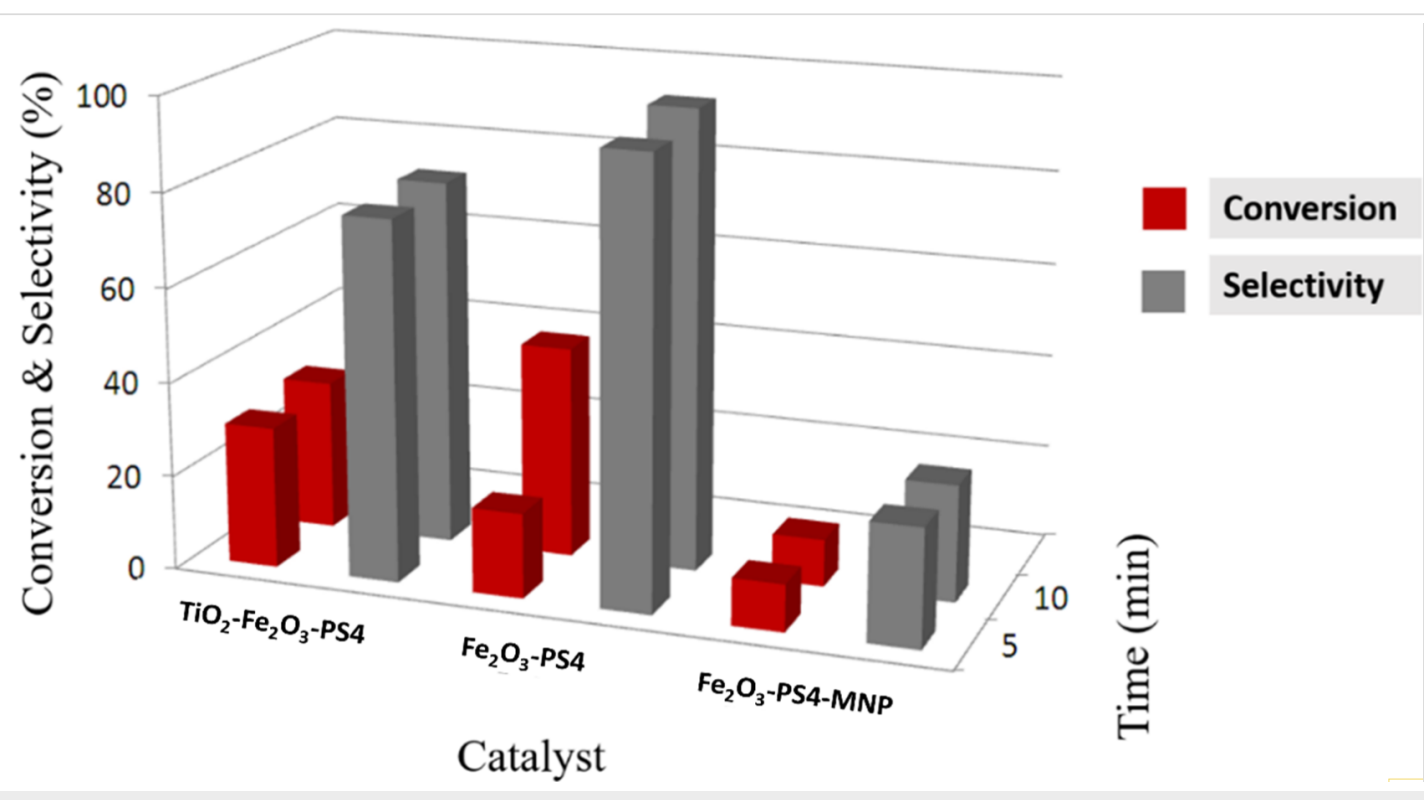

Figure 5: Conversion and selectivity of the oxidation of benzyl alcohol for the three catalytic systems.

$47 \%$, which does not compensate the energy consumption by extending the reaction time from 10 to $30 \mathrm{~min}$.

The three synthesized catalysts showed high activity in the alkylation of toluene with benzyl chloride, either via microwave-assisted or with conventional heating $\left(60^{\circ} \mathrm{C}\right)$. For the microwave-assisted reaction (Scheme 2), after three minutes, the conversion was higher than $99 \%$ for all of the three materials (Figure 6). For the $\mathrm{Fe}_{2} \mathrm{O}_{3}$-PS4-MNP nanocatalyst, even after just $1 \mathrm{~min}$, the reaction showed a conversion higher than $99 \%$. In this reaction, the three corresponding isomers (ortho, meta and para substituted) were obtained. In particular, the synthesis of the para-isomer can be achieved with high selectivity, employing the $\mathrm{TiO}_{2}-\mathrm{Fe}_{2} \mathrm{O}_{3}$-PS4 and $\mathrm{Fe}_{2} \mathrm{O}_{3}$-PS4 nanomaterials for 1 and $2 \mathrm{~min}$, respectively (Table 6).

The alkylation reaction with conventional heating (Scheme 3) was followed by gas chromatography. After $30 \mathrm{~min}$, the conversion was greater than $99 \%$ for all of the three materials and the selectivity values were slightly higher compared with the microwave-assisted reaction during $3 \mathrm{~min}$ (Table 7, Figure 7).

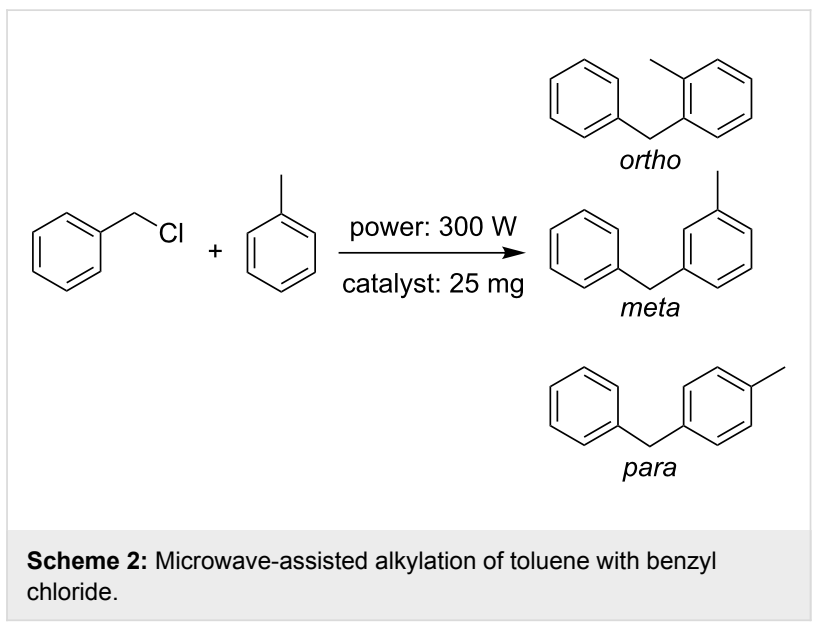

Reusability studies prove the high inherent stability and activity of $\mathrm{Fe}_{2} \mathrm{O}_{3}$-PS4-MNP and $\mathrm{TiO}_{2}-\mathrm{Fe}_{2} \mathrm{O}_{3}$-PS4 nanomaterials (Figure 8). However, the $\mathrm{Fe}_{2} \mathrm{O}_{3}$-PS4 nanocatalyst loses its activity after the first use, which can be due to the loss of residual acidity, which might happen to the material after the synthesis process. 


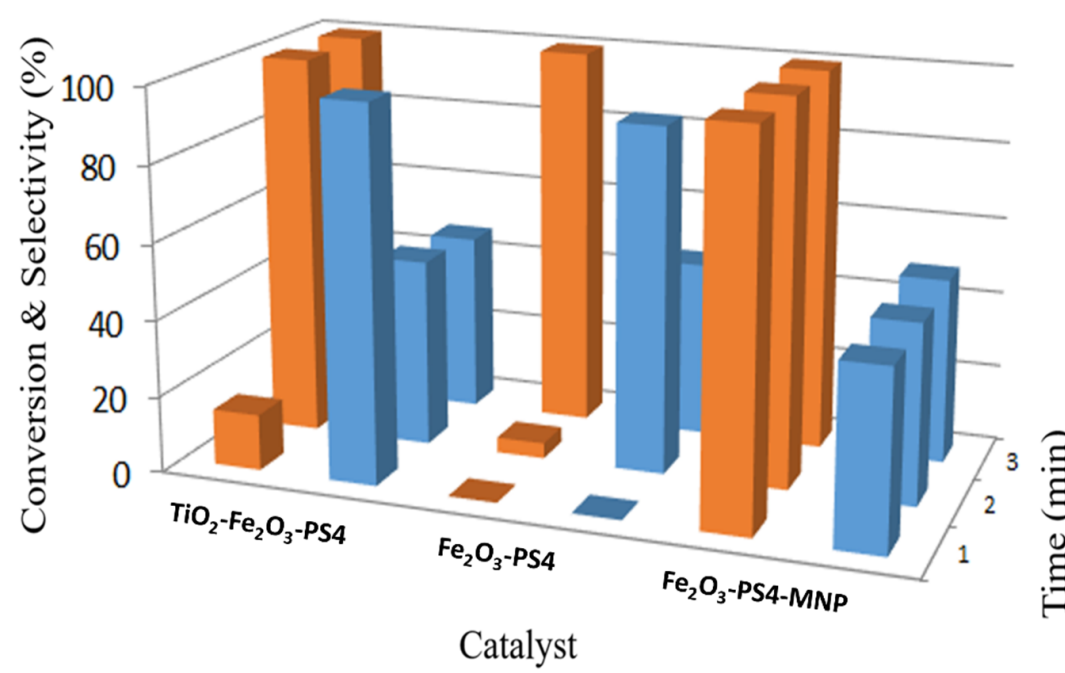

Conversion

Selectivity

Figure 6: Conversion and selectivity of the microwave-assisted alkylation of toluene for the three catalytic systems.

Table 6: Conversion and selectivity of the microwave-assisted alkylation of toluene for the three catalytic systems.

\begin{tabular}{|c|c|c|c|c|c|c|}
\hline \multirow{2}{*}{$\begin{array}{c}\text { Catalyst } \\
\text { Time (min) }\end{array}$} & \multicolumn{2}{|c|}{$\mathrm{TiO}_{2}-\mathrm{Fe}_{2} \mathrm{O}_{3}-\mathrm{PS} 4$} & \multicolumn{2}{|c|}{$\mathrm{Fe}_{2} \mathrm{O}_{3}-\mathrm{PS} 4$} & \multicolumn{2}{|c|}{$\mathrm{Fe}_{2} \mathrm{O}_{3}-\mathrm{PS} 4-\mathrm{MNP}$} \\
\hline & $\mathrm{C}^{\mathrm{a}}(\%)$ & S-p $p^{b}(\%)$ & $\mathrm{C}^{\mathrm{a}}(\%)$ & S-p $p^{b}(\%)$ & $\mathrm{C}^{\mathrm{a}}(\%)$ & S-p $p^{b}(\%)$ \\
\hline 1 & 14.6 & 97.9 & - & - & $>99$ & 46.3 \\
\hline 2 & $>99$ & 49.1 & 4 & 90.1 & $>99$ & 46.9 \\
\hline 3 & $>99$ & 46.8 & $>99$ & 46 & $>99$ & 48.4 \\
\hline
\end{tabular}

${ }^{a}$ Conversion (\%); ${ }^{b}$ selectivity (\%) with respect to the para-isomer.

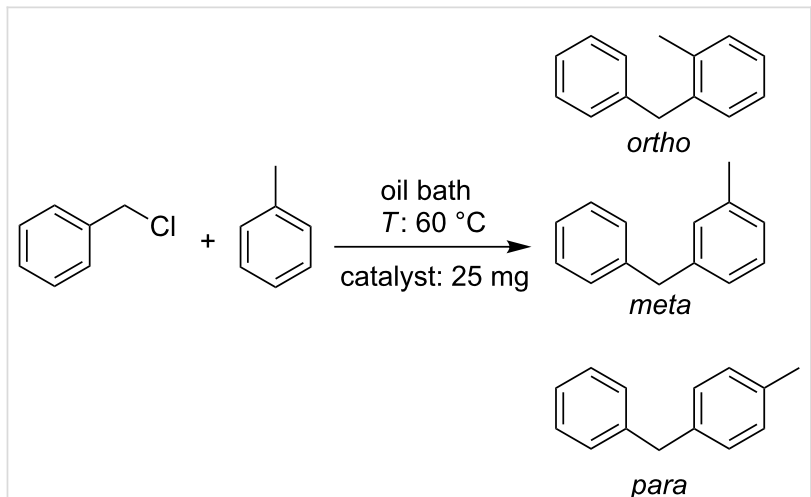

Scheme 3: Alkylation of toluene with benzyl chloride with conventional heating.
Reference experiments for the two investigated reactions were carried out in the absence of catalyst, demonstrating that the nanocomposites play a crucial role in order to accelerate the reaction rates (Supporting Information File 1, Table S1). It can be concluded that for the oxidation of benzyl alcohol, the $\mathrm{Fe}_{2} \mathrm{O}_{3}$-PS4 presents a better employability outlook, whereas for the alkylation reaction, the $\mathrm{Fe}_{2} \mathrm{O}_{3}$-PS4-MNP showed promising conversion and selectivity values.

\section{Conclusion}

The three bio-nanocomposites $\mathrm{TiO}_{2}-\mathrm{Fe}_{2} \mathrm{O}_{3}-\mathrm{PS} 4, \mathrm{Fe}_{2} \mathrm{O}_{3}$-PS4 and $\mathrm{Fe}_{2} \mathrm{O}_{3}$-PS4-MNP, based on iron oxide and polysaccharide $\mathrm{S} 4$ were synthesized by mechanochemical processes. The magnetic susceptibility measurements show attractive magnetic

Table 7: Conversion and selectivity of the alkylation of toluene with conventional heating.

\begin{tabular}{|c|c|c|c|c|c|c|}
\hline \multirow{2}{*}{$\begin{array}{l}\text { Catalyst } \\
\text { Time (min) }\end{array}$} & \multicolumn{2}{|c|}{$\mathrm{TiO}_{2}-\mathrm{Fe}_{2} \mathrm{O}_{3}-\mathrm{PS} 4$} & \multicolumn{2}{|c|}{$\mathrm{Fe}_{2} \mathrm{O}_{3}-\mathrm{PS} 4$} & \multicolumn{2}{|c|}{$\mathrm{Fe}_{2} \mathrm{O}_{3}-\mathrm{PS} 4-\mathrm{MNP}$} \\
\hline & $\mathrm{C}^{\mathrm{a}}(\%)$ & S-p $p^{b}(\%)$ & $\mathrm{C}^{\mathrm{a}}(\%)$ & S-p ${ }^{b}(\%)$ & $\mathrm{C}^{\mathrm{a}}(\%)$ & S-pb $(\%)$ \\
\hline 30 & $>99$ & 51.6 & $>99$ & 50.5 & $>99$ & 49.5 \\
\hline
\end{tabular}

aConversion (\%), bselectivity (\%) with respect to the para-isomer. 

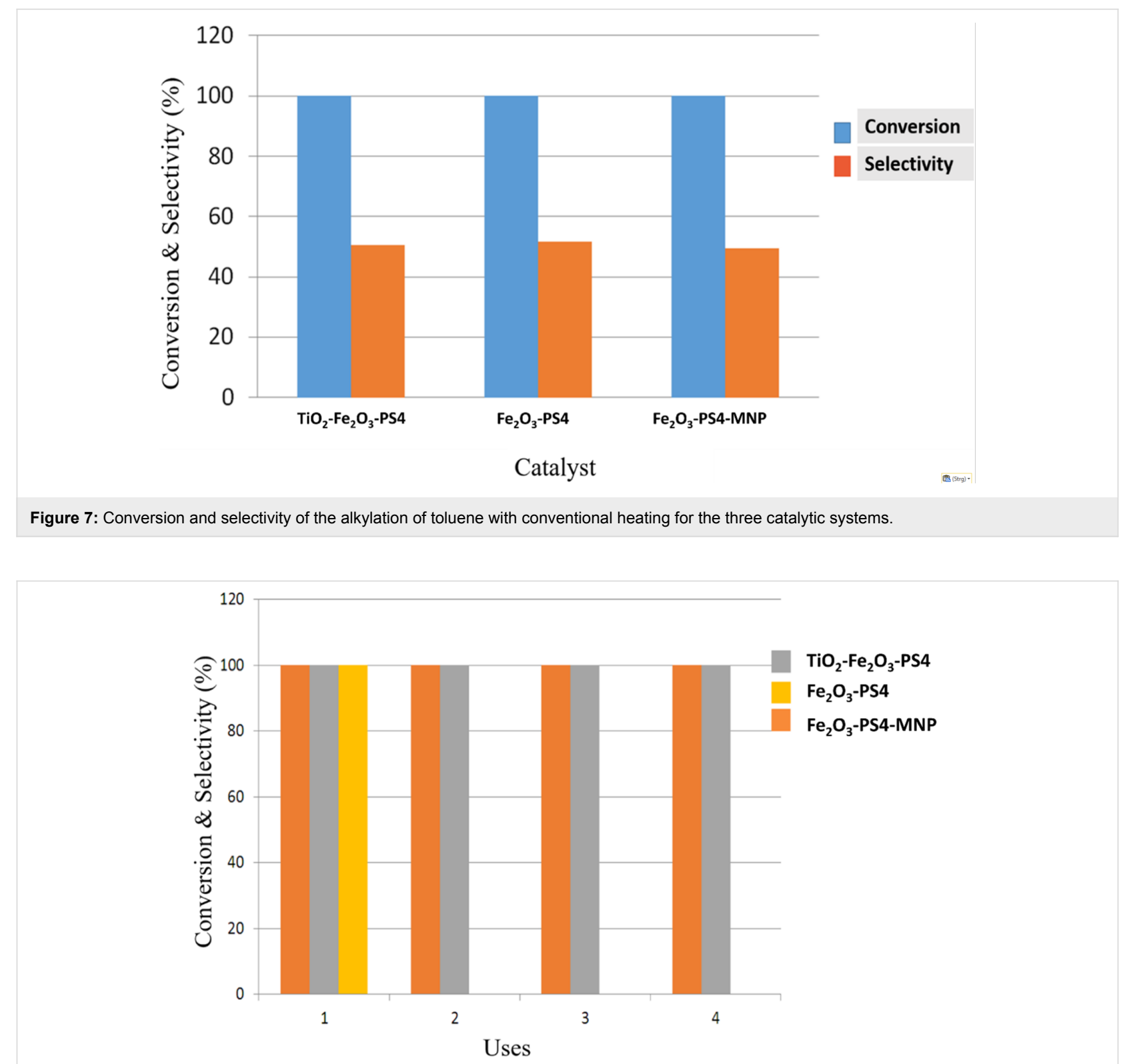

Figure 8: Reusability of the iron oxide/polysaccharide nanohybrids.

characteristics for recovery and reusability of the $\mathrm{Fe}_{2} \mathrm{O}_{3}$-PS4MNP nanocomposite. Furthermore, the nanomaterials showed promising activity in the oxidation reaction of benzyl alcohol to benzaldehyde, with conversions of $32-45 \%$. The three synthesized nanocomposites have proved to be highly active and selective catalysts in the alkylation reaction of toluene with benzyl chloride, due to the exceptional surface acidic properties of the nanoparticles. Both microwave irradiation and conventional heating exhibited high conversion and selectivity to the main product of the reaction in extremely short reaction times. Moreover, reusability studies showed high stability and activity of the nanohybrids $\mathrm{TiO}_{2}-\mathrm{Fe}_{2} \mathrm{O}_{3}$-PS4 and $\mathrm{Fe}_{2} \mathrm{O}_{3}$-PS4-MNP, establishing these catalysts as potential candidates in both the selective oxidation of benzyl alcohol and alkylation of toluene with benzyl chloride.

\section{Experimental Synthesis of bio-nanocomposites based on iron oxide and polysaccharide S4}

A simple, reproducible and environmentally friendly protocol has been developed for the synthesis of the three catalysts $\mathrm{Fe}_{2} \mathrm{O}_{3}$-PS4, $\mathrm{Fe}_{2} \mathrm{O}_{3}$-PS4-MNP, and $\mathrm{TiO}_{2}-\mathrm{Fe}_{2} \mathrm{O}_{3}$-PS4. The three materials were synthesized using a 2:1 metal precursor/polysaccharide ratio ( $2 \mathrm{~g}$ of polysaccharide $\mathrm{S} 4,4 \mathrm{~g}$ of $\mathrm{FeCl}_{2} \cdot 4 \mathrm{H}_{2} \mathrm{O}$ ), in a ball mill (Retsch PM100 ball mill model), at $350 \mathrm{rpm}$ for 30 min, using a $125 \mathrm{~mL}$ reaction chamber and $1810 \mathrm{~mm}$ stain- 
less steel balls. Additionally, in the case of the $\mathrm{TiO}_{2}-\mathrm{Fe}_{2} \mathrm{O}_{3}$ $\mathrm{PS} 4,4.08 \mathrm{~mL}$ of titanium isopropoxide was added to obtain the desired nanomaterial. Subsequently, the materials were ovendried at $100{ }^{\circ} \mathrm{C}$ for $24 \mathrm{~h}$, and finally calcined at $600{ }^{\circ} \mathrm{C}$ for $3 \mathrm{~h}$ in air atmosphere.

The $\mathrm{Fe}_{2} \mathrm{O}_{3}$-PS4-MNP catalyst was obtained using $2 \mathrm{~g}$ of polysaccharide $\mathrm{S} 4,4 \mathrm{~g}$ of $\mathrm{Fe}\left(\mathrm{NO}_{3}\right)_{3} \cdot 9 \mathrm{H}_{2} \mathrm{O}$ and $1.5 \mathrm{~mL}$ of propionic acid. The milling process was carried out at $350 \mathrm{rpm}$ for 15 and $30 \mathrm{~min}$, respectively. The resulting material was oven-dried at $100{ }^{\circ} \mathrm{C}$ for $24 \mathrm{~h}$ and slowly heated up $\left(1{ }^{\circ} \mathrm{C} / \mathrm{min}\right)$ to $300{ }^{\circ} \mathrm{C}$ under air and kept at that temperature for $30 \mathrm{~min}$.

\section{Material characterization}

In order to characterize the synthesized materials, several techniques have been employed, including XRD, XPS, absorption-desorption of $\mathrm{N}_{2}$, SEM, TEM, DRIFT and titrations with pyridine and dimethylpyridine. In addition, the magnetic susceptibility of $\mathrm{Fe}_{2} \mathrm{O}_{3}$-PS4-MNP was measured and the elemental composition of $\mathrm{TiO}_{2}-\mathrm{Fe}_{2} \mathrm{O}_{3}$-PS4 was determined by ICP-MS.

\section{X-ray diffraction}

X-ray diffraction has been used for the structural study of the synthesized nanocatalysts. The diffraction patterns were obtained on a Bruker D8 Discover diffractometer, equipped with a goniometer Bragg Brentano $\theta / \theta$ of high precision, and with a $\mathrm{Cu}$ $\mathrm{X}$-ray tube. Scans were performed in the 0.5 to $80^{\circ}$ range at a step size of $0.02^{\circ}$ with a counting time per step of $20 \mathrm{~s}$.

\section{X-ray photoelectron spectroscopy}

XPS measurements were performed at the Central Service of Research Support (SCAI) of the University of Cordoba, in an ultrahigh vacuum (UHV) multipurpose surface analysis system (SpecsTM model, Germany), operating at pressures of $<10^{-10}$ mbar, using a conventional X-ray source (XR-50, Specs, $\mathrm{Mg} \mathrm{K} \alpha, h \mathrm{v}=1253.6 \mathrm{eV}, 1 \mathrm{eV}=1.603 \times 10^{-19} \mathrm{~J}$ ) in a "stop and go" mode. Powdered samples were deposited on a sample holder using double-sided adhesive tape and subsequently evacuated overnight under vacuum $\left(<10^{-6}\right.$ Torr $)$. The spectra were taken at room temperature (pass energy: 25 and $10 \mathrm{eV}$, step size: 1 and $0.1 \mathrm{eV}$, respectively) with a Phoibos 150-MCD energy detector. For the deconvolution of the obtained curves, the XPS software CASA was used.

\section{$\mathrm{N}_{2}$ physisorption}

The Brunauer-Emmett-Teller (BET) surface area and pore volume measurements were obtained from $\mathrm{N}_{2}$ adsorption-desorption isotherms at liquid nitrogen temperature $(77 \mathrm{~K})$ in a Micromeritics ASAP 2000 instrument. The weight of the samples ranged between $0.15-0.20 \mathrm{~g}$. Prior to the analysis, the samples were degassed for $24 \mathrm{~h}$ at $140{ }^{\circ} \mathrm{C}$ under vacuum $\left(p<10^{-2} \mathrm{~Pa}\right)$. The surface areas were calculated according to the linear equation of BET in the $0.05<p_{0}<0.22$ range. The pore size distributions (PSDs) were obtained from the $\mathrm{N}_{2}$ desorption branch.

\section{Electron microscopy}

SEM images and the elemental composition were recorder using the JEOL JSM-6490 LV microscope. The samples were $\mathrm{Au} / \mathrm{Pd}$-coated on a high-resolution sputter SC7640 at a sputtering rate of $1.5 \mathrm{kV}$ per minute, up to $7 \mathrm{~nm}$ thickness. TEM micrographs were obtained in the FEI Tecnai $\mathrm{G}^{2}$ system, equipped with a charge coupling device camera. Prior to analysis, the samples were suspended in ethanol and directly deposited on a copper grid.

\section{Diffuse reflectance infrared Fourier transform spectroscopy}

The DRIFT spectra of the materials were recorder on an infrared spectrophotometer (ABB MB3000 with Horizon MBTM software), equipped with an ATR PIKE MIRacleTM sampler, with a $\mathrm{ZnSe}$ window using 256 scans at a resolution of $8 \mathrm{~cm}^{-1}$. During the measurements, the sample was purged with a nitrogen flow (20 $\mathrm{mL} \mathrm{min}{ }^{-1}$, dehydrated and deoxygenated). The spectra were recorded at room temperature in the $4000-600 \mathrm{~cm}^{-1}$ wavenumber range. The materials were heated at $300{ }^{\circ} \mathrm{C}$ for $3 \mathrm{~h}$ prior to acquiring the reference spectra. Thus, the temperature was decreased to $200{ }^{\circ} \mathrm{C}$, and after $10 \mathrm{~min}$ the reference spectrum was again recorded. Similarly, the reference spectra at 150 and $100{ }^{\circ} \mathrm{C}$ were acquired. Once the references were obtained, the acquisition of the spectra was carried out starting with the lowest temperature.

\section{Pyridine (PY) and 2,6-dimethylpyridine (DMPY) titration}

Pyridine (PY) and 2,6-dimethylpyridine (DMPY) titration experiments were carried out at $300{ }^{\circ} \mathrm{C}$, via gas phase adsorption of the basic probe molecules applying a pulse chromatographic titration methodology. The catalyst used $(\approx 0.025 \mathrm{~g})$ was fixed inside a tubular stainless steel microreactor (4 mm internal diameter) by Pyrex glass wool. A cyclohexane solution of titrant (0.989 $\mathrm{M}$ in PY and 0.686 $\mathrm{M}$ in DMPY, respectively) was injected into a gas chromatograph through a microreactor in which the catalyst was previously sited. The injected base was analyzed by gas chromatography with a flame ionization detector and using an analytical column of $0.5 \mathrm{~m}$ length, containing $5 \mathrm{wt} \%$ of polyphenylether in the Chromosorb AW-DMCS in $80 / 100$. The quantity of probe molecule adsorbed by the solid acid catalyst can subsequently be easily quantified. In order to distinguish between Lewis and Brønsted acidity, it was assumed that all DMPY selectively titrates 
Brønsted sites (methyl groups hinder coordination of nitrogen atoms with Lewis acid sites) while PY titrates both Brønsted and Lewis acid sites in the materials. Thus, the difference between the amounts of PY (total acidity) and DMPY (Brønsted acidity) adsorbed should correspond to Lewis acidity in the materials.

\section{ICP-MS}

The metal content in the $\mathrm{TiO}_{2}-\mathrm{Fe}_{2} \mathrm{O}_{3}$-PS4 catalyst was determined by ICP-MS in an Elan DRC-e (PerkinElmer SCIEX) spectrometer. The sample $(\approx 25 \mathrm{mg})$ was previously digested using an acid mixture of $\mathrm{HF} / \mathrm{HNO}_{3} / \mathrm{HCl} 1: 1: 1$. Dilutions were made with miliQ water (double distilled) up to a maximum of $1 \%$ of $\mathrm{HF}_{2}{ }^{-}$in acid solution.

\section{Magnetic susceptibility}

The magnetic susceptibility was measured at room temperature at low frequency $(470 \mathrm{~Hz})$ using a Bartington MS-2 instrument.

\section{Catalytic experiments}

The oxidation of benzyl alcohol to benzaldehyde was performed using $25 \mathrm{mg}$ of catalyst, $0.2 \mathrm{~mL}$ of benzyl alcohol, $0.3 \mathrm{~mL}$ of hydrogen peroxide, and $2 \mathrm{~mL}$ of acetonitrile as the solvent, for 5 and $10 \mathrm{~min}$, respectively.

The microwave-assisted alkylation of toluene and oxidation of benzyl alcohol was carried out in a CEM-Discover microwave reactor, equipped with a PC-controlled interface. The alkylation reactions were carried out by the standard "open vessel" method, while for oxidation reactions, the "discover" method was used under pressure, allowing us to control the irradiation power, temperature and pressure.

The alkylation reaction of toluene with benzyl chloride was performed under conventional heating, too. In both alkylation experiments, $2 \mathrm{~mL}$ of toluene, $0.2 \mathrm{~mL}$ of benzyl chloride and $25 \mathrm{mg}$ of catalyst were used. The microwave-assisted reaction was conducted for 1, 2 and $3 \mathrm{~min}$, while the reaction under conventional heating was carried out for $30 \mathrm{~min}$ until the maximum conversion was reached. The temperature in both cases was kept at around $60{ }^{\circ} \mathrm{C}$.

The conversion and selectivity were calculated from the chromatograms by:

$$
\begin{aligned}
& \text { conversion }(\%)=\left[\frac{c_{\text {initial }}-c_{\text {final }}}{c_{\text {initial }}}\right] \\
& \text { selectivity }(\%)=\frac{c_{\text {product }}}{\left[c_{\text {initial }}-c_{\text {final }}\right]} \times 100
\end{aligned}
$$

where $c_{\text {initial }}$ and $c_{\text {final }}$ are the concentrations of the reagents before and after the reaction, respectively, and $c_{\text {product }}$ is the concentration of the product, as determined by gas chromatography (GC).

The samples were analyzed with a HP5890 Series II gas chromatograph (60 mL min ${ }^{-1} \mathrm{~N}_{2}$ carrier flow, 20 psi column top head pressure) using a flame ionization detector (FID). A HP-101 capillary column $(25 \mathrm{~m} \times 0.2 \mathrm{~mm} \times 0.2 \mu \mathrm{m})$ was employed. All calculations were based on the use of benzyl chloride and benzyl alcohol as limiting reagents for the studied alkylation and oxidation reaction, respectively.

\section{Supporting Information}

\section{Supporting Information File 1}

Additional spectra.

[http://www.beilstein-journals.org/bjoc/content/ supplementary/1860-5397-13-194-S1.pdf]

\section{References}

1. White, R. J.; Luque, R.; Budarin, V. L.; Clark, J. H.; Macquarrie, D. J. Chem. Soc. Rev. 2009, 38, 481-494. doi:10.1039/B802654H

2. Astruc, D.; Lu, F.; Aranzaes, J. R. Angew. Chem., Int. Ed. 2005, 44, 7852-7872. doi:10.1002/anie.200500766

3. Grunes, J.; Zhu, J.; Somorjai, G. A. Chem. Commun. 2003, 2257-2260. doi:10.1039/b305719b

4. Anastas, P. T.; Warner, J. C. Green Chemistry: Theory and Practice; Oxford University Press: New York, 1998.

5. Xu, C.; De, S.; Balu, A. M.; Ojeda, M.; Luque, R. Chem. Commun. 2015, 51, 6698-6713. doi:10.1039/C4CC09876E

6. Astruc, D., Ed. Nanoparticles and catalysis; John Wiley \& Sons, 2008.

7. Polshettiwar, V.; Luque, R.; Fihri, A.; Zhu, H.; Bouhrara, M.; Basset, J.-M. Chem. Rev. 2011, 111, 3036-3075. doi:10.1021/cr100230z

8. Cai, D.; Mataraza, J. M.; Qin, Z. H.; Huang, Z.; Huang, J.; Chiles, T. C.; Carnahan, D.; Kempa, K.; Ren, Z. Nat. Methods 2005, 2, 449-454. doi:10.1038/nmeth761

9. Hu, X.; Dong, S. J. Mater. Chem. 2008, 18, 1279-1295. doi:10.1039/b713255g

10. Balu, A. M.; Pineda, A.; Yoshida, K.; Campelo, J. M.; Gai, P. L.; Luque, R.; Romero, A. A. Chem. Commun. 2010, 46, 7825-7827. doi:10.1039/c0cc02015j

11. Garcia-Olmo, A. J.; Yepez, A.; Balu, A. M.; Romero, A. A.; Li, Y.; Luque, R. Catal. Sci. Technol. 2016, 6, 4705-4711. doi:10.1039/C6CY00249H

12. Ouyang, W.; Kuna, E.; Yepez, A.; Balu, A. M.; Romero, A. A.; Colmenares, J. C.; Luque, R. Nanomaterials 2016, 6, 93. doi:10.3390/nano6050093

13. Colmenares, J. C.; Ouyang, W.; Ojeda, M.; Kuna, E.; Chernyayeva, O.; Lisovytskiy, D.; De, S.; Luque, R.; Balu, A. M. Appl. Catal., B: Environ. 2016, 183, 107-112. doi:10.1016/j.apcatb.2015.10.034

14. Yepez, A.; De, S.; Climent, M. S.; Romero, A. A.; Luque, R. Appl. Sci. 2015, 5, 532-543. doi:10.3390/app5030532 
15. Juárez, R.; Parker, S. F.; Concepción, P.; Corma, A.; García, H. Chem. Sci. 2010, 1, 731-738. doi:10.1039/c0sc00336k

16. Navalon, S.; Martin, R.; Alvaro, M.; Garcia, H. Angew. Chem., Int. Ed. 2010, 49, 8403-8407. doi:10.1002/anie.201003216

17. Mendes, D.; Garcia, H.; Silva, V. B.; Mendes, A.; Madeira, L. M. Ind. Eng. Chem. Res. 2009, 48, 430-439. doi:10.1021/ie8010676

18. Gonzalez-Arellano, C.; Luque, R.; Macquarrie, D. J. Chem. Commun. 2009, 1410-1412. doi:10.1039/b818767c

19. Budarin, V. L.; Clark, J. H.; Luque, R.; Macquarrie, D. J.; White, R. J. Green Chem. 2008, 10, 382-387. doi:10.1039/B715508E

20. Gonzalez-Arellano, C.; Yoshida, K.; Luque, R.; Gai, P. L. Green Chem. 2010, 12, 1281-1287. doi:10.1039/c003410j

21. Yepez, A.; Lam, F. L. Y.; Romero, A. A.; Kappe, C. O.; Luque, R. ChemCatChem 2015, 7, 276-282. doi:10.1002/cctc.201402802

22. Ozin, G. A.; Arsenault, A.; Cademartiri, L. Nanochemistry: A chemical approach to nanomaterials; Royal Society of Chemistry: Cambridge, UK, 2009.

23. Tsuzuki, T.; McCormick, P. G. J. Mater. Sci. 2004, 39, 5143-5146. doi:10.1023/B:JMSC.0000039199.56155.f9

24. Mei, K.-C.; Guo, Y.; Bai, J.; Costa, P. M.; Kafa, H.; Protti, A.; Hider, R. C.; Al-Jamal, K. T. ACS Appl. Mater. Interfaces 2015, 7, 14176-14181. doi:10.1021/acsami.5b03577

25. Ding, J.; Tsuzuki, T.; McCormick, P. G. J. Mater. Sci. 1999, 34 5293-5298. doi:10.1023/A:1004736602847

26. Koch, C. C. Nanostruct. Mater. 1993, 2, 109-129. doi:10.1016/0965-9773(93)90016-5

27. Ding, J.; Shi, Y.; Chen, L. F.; Deng, C. R.; Fuh, S. H.; Li, Y. J. Magn. Magn. Mater. 2002, 247, 249-256. doi:10.1016/S0304-8853(02)00173-7

28. Xu, C.; Ojeda, M.; Arancon, R. A. D.; Romero, A. A.; Domingo, J. L.; Gómez, M.; Blanco, J.; Luque, R. ACS Sustainable Chem. Eng. 2015, 3, 2716-2725. doi:10.1021/acssuschemeng.5b00568

29. Herea, D. D.; Chiriac, H.; Lupu, N.; Grigoras, M.; Stoian, G.; Stoica, B. A.; Petreus, T. Appl. Surf. Sci. 2015, 352, 117-125. doi:10.1016/j.apsusc.2015.03.137

30. Rodriguez-Padrón, D.; Puente-Santiago, A. R.; Balu, A. M.; Romero, A. A.; Luque, R. Chem. Commun. 2017, 53, 7635-7637. doi:10.1039/C7CC03975A

31. Rodríguez-Padrón, D.; Puente-Santiago, A. R.; Caballero, A.; Benítez, A.; Balu, A. M.; Romero, A. A.; Luque, R. J. Mater. Chem. A 2017, 5, 16404-16411. doi:10.1039/C7TA04135G

32. Huebsch, N.; Mooney, D. J. Nature 2009, 462, 426-432. doi:10.1038/nature08601

33. Salgueiriño-Maceira, V.; Correa-Duarte, M. A. Adv. Mater. 2007, 19, 4131-4144. doi:10.1002/adma.200700418

34. Zheng, Y.; Monty, J.; Linhardt, R. J. Carbohydr. Res. 2015, 405, 23-32. doi:10.1016/j.carres.2014.07.016

35. Majewski, P.; Thierry, B. Crit. Rev. Solid State Mater. Sci. 2007, 32, 203-215. doi:10.1080/10408430701776680

36. Tallury, P.; Payton, K.; Santra, S. Nanomedicine 2008, 3, 579-592. doi:10.2217/17435889.3.4.579

37. Kim, J.; Piao, Y.; Hyeon, T. Chem. Soc. Rev. 2009, 38, 372-390. doi:10.1039/B709883A

38. Pineda, A.; Balu, A. M.; Campelo, J. M.; Romero, A. A.; Carmona, D.; Balas, F.; Santamaria, J.; Luque, R. ChemSusChem 2011, 4, 1561-1565. doi:10.1002/cssc.201100265

39. Matsumoto, T.; Ueno, M.; Wang, N.; Kobayashi, S. Chem. - Asian J. 2008, 3, 196-214. doi:10.1002/asia.200700359

40. Dey, S. K.; Mukherjee, A. Coord. Chem. Rev. 2016, 310, 80-115. doi:10.1016/j.ccr.2015.11.002
41. Rajabi, F.; Naresian, S.; Primo, A.; Luque, R. Adv. Synth. Catal. 2011, 353, 2060-2066. doi:10.1002/adsc.201100149

42. Yang, J.-C. E.; Yuan, B.; Cui, H.-J.; Wang, S.; Fu, M.-L. Appl. Catal., B: Environ. 2017, 205, 327-339. doi:10.1016/j.apcatb.2016.12.046

43. Huang, X.; Wang, X.; Wang, X.; Wang, X.; Tan, M.; Ding, W.; Lu, X. J. Catal. 2013, 301, 217-226. doi:10.1016/j.jcat.2013.02.011

44. Rak, M. J.; Lerro, M.; Moores, A. Chem. Commun. 2014, 50, 12482-12485. doi:10.1039/C4CC04749D

45. Shi, F.; Tse, M. K.; Pohl, M.-M.; Brückner, A.; Zhang, S.; Beller, M. Angew. Chem., Int. Ed. 2007, 46, 8866-8868. doi:10.1002/anie.200703418

46. Campelo, J. M.; Luna, D.; Luque, R.; Marinas, J. M.; Romero, A. A. ChemSusChem 2009, 2, 18-45. doi:10.1002/cssc.200800227

47. Wilson, K.; Adams, D. J.; Rothenberg, G.; Clark, J. H. J. Mol. Catal. A 2000, 159, 309-314. doi:10.1016/S1381-1169(00)00185-0

48. Bastock, T. W.; Clark, J. H. Speciality chemicals; Elsevier Applied Science: London, New York, 1991; p 383.

49. Pineda, A.; Balu, A. M.; Campelo, J. M.; Luque, R.; Romero, A. A.; Serrano-Ruiz, J. C. Catal. Today 2012, 187, 65-69. doi:10.1016/j.cattod.2012.02.028

50. Gracia, M. J.; Losada, E.; Luque, R.; Campelo, J. M.; Luna, D.; Marinas, J. M.; Romero, A. A. Appl. Catal., A 2008, 349, 148-155. doi:10.1016/j.apcata.2008.07.023

51. Ojeda, M.; Balu, A. M.; Barrón, V.; Pineda, A.; Coleto, Á. G.; Romero, A. A.; Luque, R. J. Mater. Chem. A 2014, 2, 387-393. doi:10.1039/C3TA13564K

52. Bourlinos, A. B.; Simopoulos, A.; Boukos, N.; Petridis, D. J. Phys. Chem. B 2001, 105, 7432-7437. doi:10.1021/jp010286+

53. Gregg, S. J.; Sing, K. S. W. Adsorption, Surface Area and Porosity; Academic Press Inc.: London, 1982.

54. Luque, R.; Campelo, J. M.; Luna, D.; Marinas, J. M.; Romero, A. A. Microporous Mesoporous Mater. 2005, 84, 11-20. doi:10.1016/j.micromeso.2005.05.013

\section{License and Terms}

This is an Open Access article under the terms of the Creative Commons Attribution License (http://creativecommons.org/licenses/by/4.0), which permits unrestricted use, distribution, and reproduction in any medium, provided the original work is properly cited.

The license is subject to the Beilstein Journal of Organic Chemistry terms and conditions:

(http://www.beilstein-journals.org/bjoc)

The definitive version of this article is the electronic one which can be found at: doi:10.3762/bjoc.13.194 